\title{
Secular changes in height, weight and body mass index in Hong Kong Children
}

\author{
Hung-Kwan So ${ }^{1}$, Edmund AS Nelson*1, Albert M Li ${ }^{1}$, Eric MC Wong2, \\ Joseph TF Lau², Georgia S Guldan ${ }^{3}$, Kwok-Hang Mak, Youfa Wang5, Tai- \\ Fai Fok ${ }^{1}$ and Rita YT Sung ${ }^{1}$
}

\begin{abstract}
Address: ${ }^{1}$ Department of Paediatrics, The Chinese University of Hong Kong, Hong Kong Special Administrative Region, PR China, ${ }^{2}$ Centre for Clinical Trials and Epidemiological Research, The Chinese University of Hong Kong, Hong Kong Special Administrative Region, PR China, ${ }^{3}$ Department of Biochemistry and Food and Nutritional Sciences Programme, The Chinese University of Hong Kong, Hong Kong Special Administrative Region, PR China, ${ }^{4}$ Student Health Service, Department of Health, Government of the Hong Kong Special Administrative Region, PR China and ${ }^{5}$ Center for Human Nutrition, Department of International Health, John Hopkins Bloomberg School of Public Health, Baltimore, MD 21205, USA

Email: Hung-Kwan So - sohk@cuhk.edu.hk; Edmund AS Nelson* - tony-nelson@cuhk.edu.hk; Albert M Li - albertmli@cuhk.edu.hk; Eric MC Wong - mcwong@cuhk.edu.hk; Joseph TF Lau - jlau@cuhk.edu.hk; Georgia S Guldan - gsguldan@cuhk.edu.hk; KwokHang Mak -drkhmak@dh.gov.hk; Youfa Wang - ywang@jhsph.edu; Tai-Fai Fok - taifaifok@cuhk.edu.hk; Rita YT Sung - yntzsung@cuhk.edu.hk

* Corresponding author
\end{abstract}

Published: 21 September 2008

BMC Public Health 2008, 8:320 doi:10.1 I86/147I-2458-8-320
Received: 29 January 2008

Accepted: 2I September 2008

This article is available from: http://www.biomedcentral.com/I47I-2458/8/320

(c) 2008 So et al; licensee BioMed Central Ltd.

This is an Open Access article distributed under the terms of the Creative Commons Attribution License (http://creativecommons.org/licenses/by/2.0), which permits unrestricted use, distribution, and reproduction in any medium, provided the original work is properly cited.

\begin{abstract}
Background: Large population growth surveys of children and adolescents aged 6 to 18 y were undertaken in Hong Kong in 1963 and 1993. The global epidemic of obesity is a major public health concern. To monitor the impact of this epidemic in Hong Kong children and to identify secular changes in growth, a further growth survey was undertaken in 2005/6.
\end{abstract}

Methods: Cross-sectional height and weight measurements of 14,842 children and adolescents aged 6 to 18 y from Hong Kong's 18 districts were obtained during the 2005/6 school year. Percentile curves were constructed using LMS method and sex-specific percentile values of weightfor-age, height-for-age, and BMI-for-age were compared with those data from 1963 and 1993.

Results: Secular changes in height, weight and BMI were noted between 1963 and 1993 and between 1993 and 2005/6. In the latter period, greater changes were observed at younger ages, and particularly in boys. On an annual basis, the 1993-2005/6 changes were less than those during 1963-1993. Using the International Obesity Task Force cut-offs, $16.7 \%$ of children were overweight or obese in 2005/6, which was a $5.1 \%$ increase since 1993.

Conclusion: These data provide policy-makers with further evidence of the secular changes in child growth and the increasing obesity epidemic among Hong Kong children.

\section{Background}

The global epidemic of obesity is a major public health concern [1], and an increasingly recognised problem in children and adolescents [2,3]. The prevalence of overweight and obesity and obesity-related chronic diseases have increased in adults in China during the past decade 
[4]. Although the World Health Organization (WHO) recommends the use of body mass index (BMI) to define obesity, Hong Kong's Student Health Service (SHS) has historically used the definition of $>=120 \%$ median weight-for-height to define obesity. Routinely collected data by the SHS has shown that for the 2005/6 school year $19.4 \%$ of primary and $16.5 \%$ of secondary students were obese using this definition and the overall proportion of children defined as obese in 2005/6 had increased by $2.7 \%$ over an eight-year period (15.7\% in $1997 / 8$ to $18.4 \%$ in $2005 / 6$ ) (KH Mak, Student Health Service, Department of Health, Personal Communication). Although this routinely collected SHS data has potential to monitor trends in obesity over time, there are concerns that these data may not be representative of all Hong Kong children since only $56-58 \%$ of all Hong Kong ( $~ 80 \%$ primary, $30 \%$ secondary) school students attend the SHS and the extent and direction of any selection bias are unknown.

In 1963, a cross-sectional study of 14,686 children from 17 schools was undertaken to develop height and weight standards for Hong Kong children aged 6 to 20 y [5]. This was followed in 1993 by a Growth Survey of 25,000 children from birth to $18 \mathrm{y}$ recruited from Maternal and Child Health Centres (MCHC) and schools. These data were used to develop Hong Kong's current growth charts for weight, height, weight-for-age, weight-for-height and body mass index (BMI) [6-8]. These data also formed part of the dataset that was subsequently used to develop international BMI cut-offs [9]. The current study aimed to monitor secular changes in weight, height and BMI of Hong Kong children aged 6 to $18 \mathrm{y}$, with a particular view to documenting the extent of the evolving obesity epidemic.

\section{Methods \\ Sample size}

The study population included all school children in Hong Kong aged 6 to $18 \mathrm{y}$. Children were classified into 26 half-year age groups. As body weight can be assumed to be normally distributed, the sample size for each age group was calculated in terms of the standard deviation of the 100ath centile $\left(c_{100 \alpha^{\prime}}\right.$ alpha $=0.05$ for $95^{\text {th }}$ percentile $)$ and the age-specific standard deviation (SD), using the sample size planning formula developed by Healy [10]. Using the figures of the 1993 growth survey as inputs and applying the above formula, a sample size of 200 boys and 200 girls for each half-year age group in the range 6 to 9 y was estimated to keep the $95 \%$ confidence interval (CI) within $\pm 1.5 \mathrm{~kg}$. A sample size of 300 per group for those children aged $10 \mathrm{y}$ or above was estimated to keep the $95 \%$ CI within $\pm 3 \mathrm{~kg}$. Using these estimates, it was planned to recruit 14,000 children 6 to $18 \mathrm{y}$ old.

\section{Sampling method}

A two-stage cluster sampling method was used. Data from the Education and Manpower Bureau was used to compile a sampling frame of all schools in Hong Kong. International and English Schools Foundation schools, which partly cater for expatriate non-Chinese children, were excluded. In the first stage of the sampling, one primary school and one secondary school were randomly selected from each of the 18 Districts in Hong Kong. Selection of a school was based on computer-generated random numbers according to numbers of schools per district, and if the selected school declined to participate, the next randomly selected school was invited to participate. In the second stage, two classes in each grade were selected in collaboration with the school principal based on timetables and operational needs. All students of the selected classes were invited to join the study. This method allowed the data to be comparable with those obtained in the 1993 Growth Survey. Parents were informed about the study through a letter distributed by the school and asked to inform the school if they did not wish their child to participate. Parents were told that participating children would be given a record of their body measurements, and that any child with high blood pressure or other abnormal findings would be referred for further assessment. Parents were invited to complete a questionnaire providing demographic information including gestation and birth weight, and family or personal history related to risk factors for obesity. Verbal consent was obtained from the students who were then asked to completed a SelfAdministered Physical Activity Checklist [11], and a locally developed and validated rapid diet assessment questionnaire. Students were asked if they had attended the SHS for a physical examination during the current or previous academic year.

\section{Anthropometric measurements}

A team of eight trained research staff visited each selected school on a pre-arranged date to collect the anthropometric data. All instruments were validated following the standard methods of the manufacturers, and the balances were zero calibrated. Standing height without shoes was measured using a Harpenden Stadiometer (Holtain, UK) to the nearest $0.1 \mathrm{~cm}$. Body weight was measured with the lightest clothing to the nearest $0.1 \mathrm{~kg}$ by an electronic weighing scale (Tanita BF-522, Japan).

The reported weights of the school children in the 1993 study were adjusted by subtracting the average weight (median $0.3 \mathrm{~kg}$, inter-quartile range $0.3-0.4 \mathrm{~kg}$ ) of the lightest school uniform in each school from the observed weight [6]. To ensure comparability of the 1993 data with our data, we used the original unadjusted measured weights from the 1993 data to compare with our unadjusted weights. 


\section{Statistical analysis}

Percentile curves were constructed using LMS method. The sex-specific percentile values $\left(10^{\text {th }}, 50^{\text {th }}\right.$, and $\left.90^{\text {th }}\right)$ of weight-for-age, height-for-age, and BMI-for-age were compared with those of the 1993 data. The LMS method using maximum penalized likelihood was used to perform model fitting of the anthropometric centiles for the physical parameters [12]. The LMS method estimates the measurement centiles in terms of three age-sex-specific cubic spline curves: the $L$ curve (Box-Cox power to transform the data that follow a Normal distribution), $M$ curve (median) and $S$ curve (coefficient of variation). In brief, if $Y(t)$ denotes an independent positive data (e.g. height) at $t$ age(year), the distribution of $Y(t)$ can be summarized by a normally distributed SD score $(Z)$ as follows:

$$
Z=\frac{[Y(t) / M(t)]^{L(t)}-1}{L(t) S(t)}
$$

Once the $L(t), M(t)$, and $S(t)$ have been estimated for each age $t$, the $100 \alpha$ th centile at $t$ gestation weeks could be derived from

$$
C_{100 \alpha}(t)=M(t)\left[1+L(t) S(t) Z_{\alpha}\right]^{1 / L(t)}
$$

where $Z_{\alpha}$ is the $\alpha$ centile of the Normal distribution (for example for the $97^{\text {th }}$ centile, $\alpha=0.75$ and $Z_{\alpha}=1.88$ ).

\section{Ethics}

The study was approved by the Joint The Chinese University of Hong Kong and New Territories East Cluster Clinical Research Ethics Committee and the Ethics Committee of the Department of Health of the Hong Kong Government.

\section{Results}

Eighteen primary schools and 18 secondary schools, one from each of the 18 Hong Kong districts, participated in the study. Four (22\%) secondary and $2(11 \%)$ primary schools were Government schools, 12 (67\%) secondary and 15 (83\%) primary schools were aided schools and 2 (11\%) secondary and 1 (6\%) primary schools were private schools. Of all Hong Kong schools (excluding international and English Schools Foundation schools) 22\% of secondary and $6 \%$ of primary are Government schools, $69 \%$ of secondary and $80 \%$ of primary are aided schools and $9 \%$ of secondary and $14 \%$ of primary are private schools. A total of 14,842 students aged 6 to $18 \mathrm{y}$ from primary $(\mathrm{n}=6916$; boys $=3589$ and girls $=3327)$ and secondary $(\mathrm{n}=7926$; boys $=3883$ and girls $=4043)$ schools were enrolled. Seven percent $(n=520)$ of the primary and $10 \%(n=880)$ of the secondary school students declined to participate in the study (15\% government, $60 \%$ aided and $25 \%$ private schools). Reasons for non-participation were not recorded. Of the $85 \%$ students with valid responses, $65 \%(8199 / 12,674) \quad(65.4 \%$ primary and $64.1 \%$ secondary) reported that they had attended the SHS during the previous 12 months.

It was possible to compare the height, weight and BMI of children over three time periods, 1963, 1993 and 2005/6, with differences evident at different ages (Tables 1,2,3) [13]. The raw dataset from the 1963 study was not available, but detailed tables provided the data for comparisons of height, weight and BMI (Tables 1, 2 and 3) and calculation of $85^{\text {th }}$ and $95^{\text {th }}$ BMI centiles (Table 4 ). However it was not possible to make estimates of the percentage of overweight and obese children using different cut-offs in 1963 (Table 5).

The percentile curves for height, weight and BMI developed using the LMS method were compared for the 1993 and 2005/6 data sets (Figure 1). Percentile curves (3rd, 10th, 25th, 50th, 75th, 90th, 97th) for height, weight and BMI were developed for the 2005/6 data (Figure 2).

\section{Secular changes in height}

For each age group and for both genders, height increased significantly both from 1963 to 1993 and again from 1993 to 2005/6 (Table 1). During both periods, the height increases were greater in the younger children, and particularly in the boys, who were $3 \mathrm{~cm}$ taller at ages 12 and 13 $\mathrm{y}$, while girls' maximum height differences were $2 \mathrm{~cm}$ at age $8 \mathrm{y}$ and again at ages 12 and $13 \mathrm{y}$. To better compare changes over the two different time periods, 1963 to 1993 and 1993 to $2005 / 6$, the annual increases in height were also calculated (Table 1, Figure 3).

\section{Secular changes in weight and BMI}

For all age and gender groups, weight and BMI increased from 1963 to 1993 and again from 1993 to 2005/6 (Tables 2 and 3, Figure 3). However for the girls older than $13 \mathrm{y}$, neither the weight nor the BMI increases were significant in the latter period. For boys, however, although the weight increased significantly at all ages during the latter period, BMI increased significantly only up through age $15 \mathrm{y}$ during that time. Again, therefore as for height, during both periods, the weight and BMI increases were greater in the younger children, and particularly in the boys. The annual increases in weight and BMI tended to be greater in the earlier period, 1963 to 1993 , than in the latter period, 1993 to 2005/6 (Tables 2, 3).

\section{Increase in overweight and obesity}

The 1993 and 2005/6 datasets were analysed according to different cut-offs to define overweight and obesity to reveal the percentages of overweight or obese children and adolescents in those two surveys (Table 5) [7,9]. Further detailed comparisons of BMI by age group were made 
Table I: Comparison of mean height $(\mathrm{cm})$ of Hong Kong children and adolescents aged 6 to 18 y by gender in 1963, 1993 and 2005/6, with age groups defined as $>$ 5.5-6.5 $=6 \mathrm{y}$

\begin{tabular}{|c|c|c|c|c|c|c|c|c|c|c|c|c|c|}
\hline \multirow[b]{2}{*}{ Age } & \multicolumn{3}{|c|}{1963} & \multicolumn{3}{|c|}{1993} & \multicolumn{3}{|c|}{$2005 / 6$} & \multirow[b]{2}{*}{ dl } & \multirow[b]{2}{*}{$\mathrm{dl} / \mathrm{yr}$} & \multirow[b]{2}{*}{$\mathrm{d} 2$} & \multirow[b]{2}{*}{$\mathrm{d} 2 / \mathrm{yr}$} \\
\hline & $n$ & Mean & SD & $n$ & Mean & SD & $\mathrm{n}$ & Mean & SD & & & & \\
\hline \multicolumn{14}{|l|}{ Boys } \\
\hline 6 & 283 & 110.7 & 5.1 & 223 & 116.0 & 5.4 & 138 & 117.9 & 4.5 & $5.3 *$ & 0.18 & $1.9 *$ & 0.15 \\
\hline 7 & 742 & 115.5 & 5.3 & 643 & 120.6 & 5.6 & 483 & 122.9 & 5.8 & $5 . I^{*}$ & 0.17 & $2.2^{*}$ & 0.18 \\
\hline 8 & 1030 & 120.5 & 5.5 & 724 & 126.1 & 5.4 & 564 & 127.9 & 5.9 & $5.6^{*}$ & 0.19 & $1.8 *$ & 0.14 \\
\hline 9 & 1076 & 125.2 & 5.7 & 634 & 131.0 & 5.8 & 640 & 133.1 & 5.7 & $5.8^{*}$ & 0.19 & $2.1 *$ & 0.16 \\
\hline 10 & 1144 & 130.0 & 6.1 & 694 & 136.3 & 5.9 & 602 & 138.5 & 6.5 & $6.3^{*}$ & 0.21 & $2.1 *$ & 0.17 \\
\hline 11 & 1121 & 134.8 & 6.6 & 597 & 141.6 & 6.5 & 636 & 143.5 & 7.2 & $6.8^{*}$ & 0.23 & $1.9 *$ & 0.15 \\
\hline 12 & 1033 & 140.0 & 7.3 & 638 & 147.8 & 8.0 & 739 & 151.0 & 8.1 & $7.8^{*}$ & 0.26 & $3.2 *$ & 0.25 \\
\hline 13 & 1052 & 147.0 & 8.2 & 642 & 155.3 & 8.6 & 647 & 158.2 & 8.5 & $8.3^{*}$ & 0.28 & $3.0 *$ & 0.22 \\
\hline 14 & 1288 & 155.6 & 7.8 & 550 & 162.3 & 7.9 & 672 & 164.2 & 7.6 & $6.7^{*}$ & 0.22 & $1.9 *$ & 0.15 \\
\hline 15 & 1622 & 161.5 & 6.6 & 479 & 166.9 & 6.2 & 588 & 167.9 & 6.0 & $5.4^{*}$ & 0.18 & $1.0 *$ & 0.08 \\
\hline 16 & 1711 & 164.9 & 5.8 & 430 & 169.5 & 6.5 & 562 & 170.6 & 5.5 & $4.6^{*}$ & 0.15 & I.I* & 0.08 \\
\hline 17 & 1370 & 166.8 & 5.3 & 442 & 169.8 & 5.8 & 572 & 171.4 & 5.9 & $3.0 *$ & 0.1 & $1.6 *$ & 0.12 \\
\hline 18 & 874 & 167.0 & 5.1 & 311 & 170.7 & 5.9 & 468 & 171.7 & 5.5 & $3.7 *$ & 0.12 & $1.0 *$ & 0.08 \\
\hline \multicolumn{14}{|l|}{ Girls } \\
\hline 6 & 282 & 110.0 & 4.7 & 211 & 115.4 & 5.5 & 128 & 117.3 & 5.0 & $5.4^{*}$ & 0.18 & $1.9 *$ & 0.15 \\
\hline 7 & 742 & 114.7 & 5.1 & 553 & 119.8 & 5.1 & 488 & 120.8 & 5.3 & $5.1 *$ & 0.17 & $0.9 *$ & 0.08 \\
\hline 8 & 970 & 120.0 & 5.6 & 647 & 125.2 & 5.6 & 471 & 127.2 & 5.5 & $5.2 *$ & 0.17 & $2.0 *$ & 0.15 \\
\hline 9 & 1022 & 125.1 & 6.2 & 617 & 131.1 & 6.3 & 601 & 132.7 & 6.3 & $6.0 *$ & 0.2 & $1.7 *$ & 0.12 \\
\hline 10 & 1178 & 130.5 & 6.7 & 633 & 137.1 & 6.9 & 554 & 138.4 & 6.8 & $6.6^{*}$ & 0.22 & $1.3 *$ & 0.1 \\
\hline 11 & 1312 & 136.6 & 7.2 & 584 & 143.7 & 7.2 & 584 & 145.4 & 7.0 & $7.1^{*}$ & 0.24 & $1.7^{*}$ & 0.13 \\
\hline 12 & 1340 & 144.0 & 7.5 & 579 & 149.6 & 6.7 & 734 & 151.5 & 6.4 & $5.6^{*}$ & 0.19 & $1.9 *$ & 0.15 \\
\hline 13 & 1159 & 150.0 & 6.9 & 633 & 153.2 & 5.9 & 640 & 155.2 & 6.0 & $3.2 *$ & 0.11 & $2.0 *$ & 0.15 \\
\hline 14 & 1152 & 154.0 & 6.1 & 617 & 156.3 & 5.4 & 667 & 157.0 & 5.3 & $2.3^{*}$ & 0.08 & $0.8^{*}$ & 0.05 \\
\hline 15 & 1275 & 155.4 & 5.4 & 552 & 157.0 & 5.3 & 637 & 157.9 & 5.2 & $1.6 *$ & 0.05 & $1.0 *$ & 0.07 \\
\hline 16 & 1267 & 155.6 & 5 & 520 & 157.3 & 5.1 & 590 & 158.4 & 5.4 & $1.7 *$ & 0.06 & I.I* & 0.08 \\
\hline 17 & 984 & 155.6 & 4.9 & 536 & 157.8 & 5.3 & 642 & 158.7 & 5.4 & $2.2^{*}$ & 0.07 & $0.9 *$ & 0.07 \\
\hline 18 & 614 & 155.6 & 4.7 & 334 & 158.3 & 5.3 & 453 & 158.7 & 5.7 & $2.7^{*}$ & 0.09 & 0.4 & 0.03 \\
\hline
\end{tabular}

*: p-value $<0.05$

dl: Difference of mean between 1963 and 1993

d2: Difference of mean between 1993 and 2005/6

$\mathrm{dI} / \mathrm{yr}$ : Annual changes between 1963 to 1993

d2/yr: Annual changes between 1993 to 2005/6

with recently published data from mainland China, which showed similar proportions of children having BMI above the $85^{\text {th }}$ and $95^{\text {th }}$ centiles (Table 4) [14]. Of the subsample of 8199 students who had attended the SHS during the current or previous year, $14.4 \%$ were $>=120 \%$ median weight-for-height, the SHS criteria to define obesity (Table 5).

\section{Discussion}

Our 2005/6 data collected from a large representative sample of Hong Kong children show that secular changes in linear growth continue, but of concern is the steady increase in the prevalence of overweight and obesity. Although the International Obesity Task Force (IOTF) cutoffs for overweight and obesity are useful for international comparisons, and comparisons over time, these cut-offs do not necessarily equate to children at risk of the complications of obesity. In April 2006, WHO launched new
Child Growth Standards (CGS) based on data from 8440 children in six countries raised in environments that promote healthy growth (breastfeeding, good diets, prevention of infections and healthy mothers who do not smoke) [15]. Recognising that using descriptive data from populations that reflect secular trends towards overweight and obesity to construct growth references will inadvertently result in upward skewness that will lead to an underestimation of overweight and obesity and an over-estimation of under-nutrition, WHO has also constructed and recommended new growth references for school-aged children and adolescents aged 5 to 19 y $[16,17]$. These new references accord with the new pre-school WHO CGS and BMI cut-offs for adults.

Although our estimates of the prevalence of overweight and obesity varied when different criteria were used, the gender differences persisted irrespective of the cut-off 
Table 2: Comparison of mean weight (kg) of Hong Kong children and adolescents aged 6 to 18 y by gender in 1963, 1993 and 2006, with age groups defined as $>5.5-6.5=6 \mathrm{y}$

\begin{tabular}{|c|c|c|c|c|c|c|c|c|c|c|c|c|c|}
\hline \multirow[b]{2}{*}{ Age } & \multicolumn{3}{|c|}{1963} & \multicolumn{3}{|c|}{1993} & \multicolumn{3}{|c|}{$2005 / 6$} & \multirow[b]{2}{*}{ dl } & \multirow[b]{2}{*}{$\mathrm{dl} / \mathrm{yr}$} & \multirow[b]{2}{*}{$\mathrm{d} 2$} & \multirow[b]{2}{*}{$\mathrm{d} 2 / \mathrm{yr}$} \\
\hline & $N$ & Mean & SD & $n$ & Mean & SD & $n$ & Mean & SD & & & & \\
\hline \multicolumn{14}{|c|}{ Boys } \\
\hline 6 & 283 & 17.5 & 1.5 & 223 & 21.3 & 4.5 & 138 & 22.4 & 3.3 & $3.8^{*}$ & 0.13 & $1.1 *$ & 0.08 \\
\hline 7 & 742 & 19.0 & 2.2 & 643 & 22.9 & 4.5 & 483 & 24.9 & 5.7 & $3.9 *$ & 0.13 & $2.0^{*}$ & 0.15 \\
\hline 8 & 1030 & 20.6 & 2.6 & 724 & 25.7 & 5.2 & 564 & 27.7 & 6.4 & $5 . I^{*}$ & 0.17 & $2.0^{*}$ & 0.15 \\
\hline 9 & 1076 & 22.4 & 3.1 & 634 & 28.8 & 6.5 & 640 & 30.5 & 6.7 & $6.4^{*}$ & 0.21 & $1.7^{*}$ & 0.13 \\
\hline 10 & 1144 & 24.6 & 3.9 & 694 & 32.4 & 8.0 & 602 & 35.5 & 9.2 & $7.8^{*}$ & 0.26 & $3.1 *$ & 0.24 \\
\hline 11 & $|12|$ & 27.1 & 4.8 & 597 & 36.3 & 8.9 & 636 & 38.8 & 9.8 & $9.2^{*}$ & 0.31 & $2.5^{*}$ & 0.19 \\
\hline 12 & 1033 & 30.0 & 5.9 & 638 & 39.9 & 10.0 & 739 & 44.4 & 10.8 & $9.9^{*}$ & 0.33 & $4.5^{*}$ & 0.35 \\
\hline 13 & 1052 & 34.5 & 7.0 & 642 & 44.9 & 10.8 & 647 & 49.4 & 12.3 & $10.4^{*}$ & 0.35 & $4.5^{*}$ & 0.35 \\
\hline 14 & 1288 & 40.0 & 6.8 & 550 & 50.5 & 10.5 & 672 & 53.3 & 11.0 & $10.5^{*}$ & 0.35 & $2.8^{*}$ & 0.22 \\
\hline 15 & 1622 & 45.6 & 6.4 & 479 & 53.8 & 10.4 & 588 & 57.3 & 11.5 & $8.2^{*}$ & 0.27 & $3.5^{*}$ & 0.27 \\
\hline 16 & 1711 & 49.0 & 6.0 & 430 & 57.5 & 9.8 & 562 & 59.5 & 11.2 & $8.5^{*}$ & 0.28 & $2.0^{*}$ & 0.15 \\
\hline 17 & 1370 & 51.3 & 5.9 & 442 & 59.1 & 9.1 & 572 & 61.3 & 11.6 & $7.8^{*}$ & 0.26 & $2.2^{*}$ & 0.17 \\
\hline 18 & 874 & 52.3 & 5.9 & 311 & 60.3 & 9.4 & 468 & 62.0 & 10.5 & $8.0^{*}$ & 0.27 & $1.7^{*}$ & 0.13 \\
\hline \multicolumn{14}{|c|}{ Girls } \\
\hline 6 & 282 & 16.9 & 1.7 & 211 & 20.2 & 3.5 & 128 & 21.3 & 4.0 & $3.3^{*}$ & 0.11 & $1.1 *$ & 0.08 \\
\hline 7 & 742 & 18.3 & 2.3 & 553 & 22.1 & 4.3 & 488 & 23.0 & 4.7 & $3.8^{*}$ & 0.13 & $1.0 *$ & 0.07 \\
\hline 8 & 970 & 20.2 & 2.9 & 647 & 24.9 & 5.1 & $47 \mid$ & 26.1 & 5.1 & $4.7^{*}$ & 0.16 & $1.2^{*}$ & 0.09 \\
\hline 9 & 1022 & 22.4 & 3.5 & 617 & 27.9 & 6.2 & 601 & 29.5 & 6.4 & $5.5^{*}$ & 0.18 & $1.6^{*}$ & 0.12 \\
\hline 10 & 1178 & 25.0 & 4.2 & 633 & 31.4 & 7.1 & 554 & 33.2 & 7.8 & $6.4^{*}$ & 0.21 & $1.8 *$ & 0.14 \\
\hline 11 & 1312 & 28.0 & 5.4 & 584 & 35.9 & 8.5 & 584 & 37.2 & 8.3 & $7.9^{*}$ & 0.26 & $1.3^{*}$ & 0.10 \\
\hline 12 & 1340 & 32.7 & 6.8 & 579 & 40.3 & 8.7 & 734 & 42.6 & 9.6 & $7.6^{*}$ & 0.25 & $2.3^{*}$ & 0.18 \\
\hline 13 & 1159 & 37.3 & 6.9 & 633 & 44.3 & 9.7 & 640 & 46.5 & 8.8 & $7.0^{*}$ & 0.23 & $2.2^{*}$ & 0.17 \\
\hline 14 & 1152 & 41.4 & 6.3 & 617 & 47.6 & 8.4 & 667 & 48.4 & 8.5 & $6.2^{*}$ & 0.21 & 0.7 & 0.06 \\
\hline 15 & 1275 & 43.6 & 5.7 & 552 & 48.7 & 7.0 & 637 & 49.5 & 8.9 & $5.1^{*}$ & 0.17 & 0.8 & 0.06 \\
\hline 16 & 1267 & 44.5 & 5.3 & 520 & 49.5 & 7.4 & 590 & 51.1 & 9.1 & $5.0 *$ & 0.17 & $1.7^{*}$ & 0.12 \\
\hline 17 & 984 & 45.1 & 5.1 & 536 & 50.5 & 7.2 & 642 & 51.1 & 9.5 & $5.4^{*}$ & 0.18 & 0.6 & 0.05 \\
\hline 18 & 614 & 45.5 & 5.1 & 334 & 51.0 & 6.9 & 453 & 51.3 & 8.3 & $5.5^{*}$ & 0.18 & 0.4 & 0.02 \\
\hline
\end{tabular}

*: p-value $<0.05$

dI: Difference of mean between 1963 and 1993

d2: Difference of mean between 1993 and 2005/6

dI/yr: Annual changes between 1963 to 1993

d2/yr: Annual changes between 1993 to 2005/6

(Table 5). Using the IOTF cut-offs, $16.7 \%$ of Hong Kong children $(20.9 \%$ in boys and $13.5 \%$ in girls) were overweight or obese and $3.7 \%$ were obese in $2005 / 6$, while in 1993 the figures were $11.6 \%$ ( $13.8 \%$ in boys and $9.5 \%$ in girls) and $2.6 \%$, respectively [9]. Using the definition of "weight $>=120 \%$ of median weight-for-height", which is the measure used by the Hong Kong SHS, $14.2 \%$ of children were overweight/obese in 2005/6, compared to $10.7 \%$ in 1993 . However routine data collected by the SHS for $2005 / 6$ showed that $18.4 \%$ of school children were classified as overweight/obese based on this definition (KH Mak, Student Health Service, Department of Health, Personal Communication, Table 5). This discrepancy implies a systematic bias in either or both samples, and has important implications for using the SHS data to monitor the obesity epidemic. Although $65 \%$ of our sample who responded to the question "whether they had attended SHS for physical examination in the previous year" was similar to the SHS estimate of $56-58 \%$ for $2004 / 5$, the proportion of primary attendees was less (65\% versus $80 \%$ ) and the secondary attendees was more (64\% versus $30 \%$ ). Also it was possible that students may have misinterpreted the question on whether they had attended the SHS for physical examination in the current or previous year. Although all SHS attendees have their weight and height measured annually, they will only have a detailed physical examination by a doctor every second year. Further study is therefore warranted to establish whether normal weight students are less likely to attend the SHS, or whether overweight children are less likely to enrol in a school-based study such as ours.

There is no universally agreed definition of overweight and obesity [18]. However despite limitations, BMI is considered a valid and feasible indirect measure of body fatness. The IOTF BMI cut-offs provide a common set of 
Table 3: Comparison of mean body mass index (BMI, kg/m²) of Hong Kong children and adolescents aged 6 to 18 y by gender in 1963 , 1993 and 2006, with age groups defined as $>5.5-6.5=6 \mathrm{y}$

\begin{tabular}{|c|c|c|c|c|c|c|c|c|c|c|c|c|c|}
\hline \multirow[b]{2}{*}{ Age } & \multicolumn{3}{|c|}{1963} & \multicolumn{3}{|c|}{1993} & \multicolumn{3}{|c|}{$2005 / 6$} & \multirow[b]{2}{*}{$\mathrm{dl}$} & \multirow[b]{2}{*}{$\mathrm{dl} / \mathrm{yr}$} & \multirow[b]{2}{*}{$\mathrm{d} 2$} & \multirow[b]{2}{*}{$\mathrm{d} 2 / \mathrm{yr}$} \\
\hline & $n$ & Mean & SD & $\mathrm{n}$ & Mean & SD & $n$ & Mean & SD & & & & \\
\hline \multicolumn{14}{|c|}{ Boys } \\
\hline 6 & 283 & 14.1 & 1.0 & 223 & 15.7 & 2.0 & 138 & 16.0 & 1.9 & $1.6^{*}$ & 0.05 & 0.3 & 0.02 \\
\hline 7 & 742 & 14.1 & 1.0 & 643 & 15.7 & 2.3 & 483 & 16.4 & 2.7 & $1.5^{*}$ & 0.05 & $0.7^{*}$ & 0.05 \\
\hline 8 & 1030 & 14.3 & 1.2 & 724 & 16.0 & 2.4 & 564 & 16.8 & 2.7 & $1.8^{*}$ & 0.06 & $0.7^{*}$ & 0.06 \\
\hline 9 & 1076 & 14.9 & I.I & 634 & 16.6 & 2.9 & 640 & 17.1 & 2.8 & $1.8^{*}$ & 0.06 & $0.4^{*}$ & 0.04 \\
\hline 10 & 1144 & 14.6 & 1.4 & 694 & 17.3 & 3.2 & 602 & 18.3 & 3.6 & $2.7^{*}$ & 0.09 & $1.0^{*}$ & 0.08 \\
\hline 11 & $|1| 2 \mid$ & 14.6 & 1.6 & 597 & 18.0 & 3.4 & 636 & 18.7 & 3.5 & $3.4^{*}$ & 0.11 & $0.7^{*}$ & 0.05 \\
\hline 12 & 1033 & 15.4 & 1.8 & 638 & 18.1 & 3.4 & 739 & 19.3 & 3.6 & $2.7^{*}$ & 0.09 & $1.2^{*}$ & 0.09 \\
\hline 13 & 1052 & 16.1 & 1.9 & 642 & 18.4 & 3.4 & 647 & 19.5 & 3.7 & $2.4^{*}$ & 0.08 & I.I* & 0.08 \\
\hline 14 & 1288 & 16.7 & 1.8 & 550 & 19.0 & 3.2 & 672 & 19.7 & 3.4 & $2.3^{*}$ & 0.08 & $0.6^{*}$ & 0.05 \\
\hline 15 & 1622 & 17.4 & 1.8 & 479 & 19.3 & 3.3 & 588 & 20.3 & 3.6 & $1.8^{*}$ & 0.06 & $1.0 *$ & 0.08 \\
\hline 16 & 1711 & 17.9 & 1.9 & 430 & 20.0 & 3.0 & 562 & 20.4 & 3.5 & $2.1^{*}$ & 0.07 & 0.4 & 0.03 \\
\hline 17 & 1370 & 18.4 & 1.9 & 442 & 20.5 & 2.9 & 572 & 20.8 & 3.6 & $2.1^{*}$ & 0.07 & 0.4 & 0.02 \\
\hline 18 & 874 & 18.7 & 1.8 & 311 & 20.7 & 2.8 & 468 & 21.0 & 3.3 & $2.0^{*}$ & 0.07 & 0.4 & 0.02 \\
\hline \multicolumn{14}{|c|}{ Girls } \\
\hline 6 & 282 & 13.8 & 1.0 & 211 & 15.1 & 1.5 & 128 & 15.4 & 2.0 & $1.3^{*}$ & 0.04 & 0.3 & 0.02 \\
\hline 7 & 742 & 13.9 & 1.0 & 553 & 15.3 & 2.3 & 488 & 15.7 & 2.4 & $1.4^{*}$ & 0.05 & $0.4^{*}$ & 0.03 \\
\hline 8 & 970 & 14.0 & 1.1 & 647 & 15.8 & 2.4 & 471 & 16.0 & 2.4 & $1.8^{*}$ & 0.06 & 0.3 & 0.02 \\
\hline 9 & 1022 & 14.3 & 1.3 & 617 & 16.1 & 2.5 & 601 & 16.6 & 2.6 & $1.9 *$ & 0.06 & $0.5^{*}$ & 0.04 \\
\hline 10 & 1178 & 14.5 & 1.4 & 633 & 16.6 & 2.7 & 554 & 17.2 & 3.0 & $2.0^{*}$ & 0.07 & $0.6^{*}$ & 0.05 \\
\hline 11 & 1312 & 15.0 & 1.6 & 584 & 17.2 & 3.0 & 584 & 17.5 & 2.9 & $2.2^{*}$ & 0.07 & 0.2 & 0.02 \\
\hline 12 & 1340 & 15.6 & 1.9 & 579 & 17.9 & 3.0 & 734 & 18.4 & 3.3 & $2.3^{*}$ & 0.08 & $0.5^{*}$ & 0.04 \\
\hline 13 & 1159 & 16.5 & 2.0 & 633 & 18.8 & 3.4 & 640 & 19.2 & 3.2 & $2.3^{*}$ & 0.08 & $0.5^{*}$ & 0.03 \\
\hline 14 & 1152 & 17.4 & 2.1 & 617 & 19.5 & 3.0 & 667 & 19.6 & 3.0 & $2.1^{*}$ & 0.07 & 0.1 & 0.01 \\
\hline 15 & 1275 & 18.0 & 2.0 & 552 & 19.7 & 2.6 & 637 & 19.8 & 3.1 & $1.7^{*}$ & 0.06 & 0.1 & 0.01 \\
\hline 16 & 1267 & 18.4 & 2.0 & 520 & 20.0 & 2.8 & 590 & 20.4 & 3.4 & $1.6^{*}$ & 0.05 & $0.4^{*}$ & 0.03 \\
\hline 17 & 984 & 18.6 & 1.9 & 536 & 20.3 & 2.7 & 642 & 20.3 & 3.6 & $1.7^{*}$ & 0.06 & 0 & 0 \\
\hline 18 & 614 & 18.8 & 2.0 & 334 & 20.3 & 2.5 & 453 & 20.4 & 2.8 & $1.6^{*}$ & 0.05 & 0.1 & 0.01 \\
\hline
\end{tabular}

*: p-value $<0.05$

dI: Difference of mean between 1963 and 1993

d2: Difference of mean between 1993 and 2005/6

$\mathrm{dI} / \mathrm{yr}:$ Annual changes between 1963 to 1993

d2/yr: Annual changes between 1993 to 2005/6

references that help to make international comparisons [18]. For example recent IOTF data suggest that between $1.6 \%$ (in Africa) and 28\% (in the Americas) of children are overweight and $0.2 \%$ (in Africa) and $9.6 \%$ (in the Americas) are obese. It has been projected that the prevalence of overweight and obesity for 2010 will increase to $46 \%$ and $15 \%$ (in the Americas) and 23\% and 5.3\% (in South East Asia), respectively [17]. Although the prevalence in Hong Kong may not be as high as in some other countries, the approximate 0.5 percentage point rate of annual increase in the prevalence over the past decade is similar to that of countries such as the United States, which is a cause for great concern. Ethnic differences also need to be considered when interpreting data, since Asian adults appear to experience the adverse effects of overweight and obesity at lower BMI cut-offs than do Caucasians [19]. However, even within different Asian populations there are significant differences in size and morbidity risk relationships so it has been difficult to define BMI cut-points that apply to all Asian populations for predicting increased health risks [20].

Our data suggests that the proportional increase in overweight and obesity has been greatest in the youngest children (Table 3). Three possible explanations for this greater difference in younger children can be considered. First, it is possible that children are experiencing the adiposity rebound at a younger age, but then they level off and are not significantly more overweight or obese than they were in 1993 in the older age groups. Second, children may be starting puberty earlier, although it is controversial whether there is any causal relationship between early maturation and obesity [21]. Third, we may be witnessing the effect of an advancing wave of the obesity epidemic. Younger children in our present cohort, that are taller and heavier than similar aged children in 1993, may reflect the 
Table 4: Age-sex-specific body mass index (BMI) percentiles for Hong Kong in 1993 and 2005/6 and for mainland China in 2005 for children and adolescents aged 7 to 18 y [14]

\begin{tabular}{|c|c|c|c|c|c|c|c|c|}
\hline \multirow[t]{2}{*}{ Age (years) } & \multicolumn{2}{|c|}{ Hong Kong 1963} & \multicolumn{2}{|c|}{ Hong Kong 1993} & \multicolumn{2}{|c|}{ Hong Kong 2005/6 } & \multicolumn{2}{|c|}{ China 2005} \\
\hline & $P_{85}$ & $P_{95}$ & $P_{85}$ & $P_{95}$ & $P_{85}$ & $P_{95}$ & $P_{85}$ & $P_{95}$ \\
\hline \multicolumn{9}{|l|}{ Boys } \\
\hline 7 & 15.1 & 16.1 & 17.9 & 19.6 & 18.8 & 21.4 & 17.0 & 19.6 \\
\hline 8 & 15.5 & 16.7 & 18.4 & 20.3 & 19.4 & 22.2 & 17.7 & 20.4 \\
\hline 9 & 15.5 & 16.6 & 19.1 & 21.2 & 20.1 & 23.1 & 18.4 & 21.3 \\
\hline 10 & 15.9 & 17.1 & 19.7 & 22.2 & 20.9 & 24.1 & 19.4 & 22.2 \\
\hline II & 16.6 & 18.1 & 20.3 & 23.0 & 21.6 & 25.0 & 20.1 & 23.0 \\
\hline 12 & 17.2 & 18.9 & 20.8 & 23.7 & 22.3 & 25.7 & 21.0 & 23.9 \\
\hline 13 & 18.0 & 19.8 & 21.3 & 24.4 & 22.7 & 26.2 & 21.9 & 25.0 \\
\hline 14 & 18.5 & 20.2 & 21.9 & 25.1 & 23.1 & 26.6 & 22.8 & 25.9 \\
\hline 15 & 19.2 & 20.9 & 22.3 & 25.6 & 23.5 & 26.9 & 23.5 & 26.8 \\
\hline 16 & 19.9 & 21.7 & 22.8 & 26.1 & 23.7 & 27.2 & 24.2 & 27.7 \\
\hline 17 & 20.3 & 22.1 & 23.2 & 26.4 & 23.9 & 27.3 & 25.0 & 28.5 \\
\hline 18 & 20.5 & 22.2 & 23.4 & 26.6 & 24.1 & 27.3 & 24.8 & 28.2 \\
\hline \multicolumn{9}{|l|}{ Girls } \\
\hline 7 & 14.9 & 15.9 & 17.2 & 19.1 & 17.7 & 19.8 & 16.4 & 18.3 \\
\hline 8 & I5.I & 16.2 & 17.6 & 19.6 & 18.3 & 20.6 & 17.0 & 19.0 \\
\hline 9 & 15.5 & 16.7 & 18.0 & 20.3 & 18.9 & 21.4 & 17.7 & 19.8 \\
\hline 10 & 15.9 & 17.2 & 18.7 & 21.2 & 19.6 & 22.2 & 18.4 & 20.7 \\
\hline II & 16.6 & 18.1 & 19.5 & 22.3 & 20.3 & 23.1 & 19.1 & 21.8 \\
\hline 12 & 17.5 & 19.3 & 20.4 & 23.4 & 21.1 & 24.0 & 20.0 & 22.7 \\
\hline 13 & 18.5 & 20.4 & 21.3 & 24.3 & 21.9 & 24.9 & 20.9 & 23.5 \\
\hline 14 & 19.5 & 21.5 & 22.1 & 24.8 & 22.5 & 25.5 & 21.9 & 24.4 \\
\hline 15 & 20.0 & 21.9 & 22.5 & 25.1 & 22.9 & 25.8 & 22.9 & 25.3 \\
\hline 16 & 20.4 & 22.3 & 22.7 & 25.1 & 23.1 & 26.0 & 23.9 & 26.2 \\
\hline 17 & 20.5 & 22.3 & 22.8 & 25.2 & 23.2 & 26.0 & 24.4 & 27.0 \\
\hline 18 & 20.8 & 22.7 & 23.0 & 25.2 & 23.2 & 25.9 & 24.2 & 28.0 \\
\hline
\end{tabular}

$P_{85}: 8^{\text {th }}$ percentile, overweight

$\mathrm{P}_{95}: 95^{\text {th }}$ percentile, obesity

Table 5: Overweight and obesity prevalence by gender in Hong Kong children and adolescents using different cut-offs, for data from 1993 and 2006

\begin{tabular}{|c|c|c|c|c|c|c|}
\hline & \multicolumn{2}{|c|}{ Boys } & \multicolumn{2}{|c|}{ Girls } & \multicolumn{2}{|c|}{ Total } \\
\hline & 1993 & $2005 / 6$ & 1993 & $2005 / 6$ & 1993 & $2005 / 6$ \\
\hline \multicolumn{7}{|l|}{ International Obesity Task Force cut-offs[9] } \\
\hline Overweight only (equivalent to adult BMI $25-30$ ) & $10.4 \%$ & $15.8 \%$ & $7.7 \%$ & $10.1 \%$ & $9.0 \%$ & $13.0 \%$ \\
\hline Obese only (equivalent to adult $\mathrm{BMI}>=30$ ) & $3.4 \%$ & $5.1 \%$ & $1.8 \%$ & $2.4 \%$ & $2.6 \%$ & $3.7 \%$ \\
\hline Overweight and obesity (equivalent to adult BMI >= 25) & $13.8 \%$ & $20.9 \%$ & $9.5 \%$ & $13.5 \%$ & $11.6 \%$ & $16.7 \%$ \\
\hline \multicolumn{7}{|l|}{ Overweight and obese defined as $>=\mid 20 \%$ median weight-for-height } \\
\hline Total sample & $12.0 \%$ & $17.4 \%$ & $9.4 \%$ & $11.0 \%$ & $10.7 \%$ & $14.2 \%$ \\
\hline $\begin{array}{l}\text { Sub-sample of students reporting attendance to Student Health Service during previous } \\
\text { year }(n=8199) \text { (see text) }\end{array}$ & - & $18.1 \%$ & - & $10.7 \%$ & - & $14.4 \%$ \\
\hline Student Health Service estimate * & - & - & - & - & - & $18.4 \%$ \\
\hline \multicolumn{7}{|l|}{ Percentiles based on 1993 data } \\
\hline$>=85^{\text {th }}$ percentile & $16.7 \%$ & $25.2 \%$ & $16.7 \%$ & $20.6 \%$ & $16.7 \%$ & $22.9 \%$ \\
\hline$>=95^{\text {th }}$ percentile & $7.7 \%$ & $11.8 \%$ & $6.6 \%$ & $8.4 \%$ & $7.1 \%$ & $10.1 \%$ \\
\hline
\end{tabular}

* KH Mak, Student Health Service, Department of Health, Personal Communication 

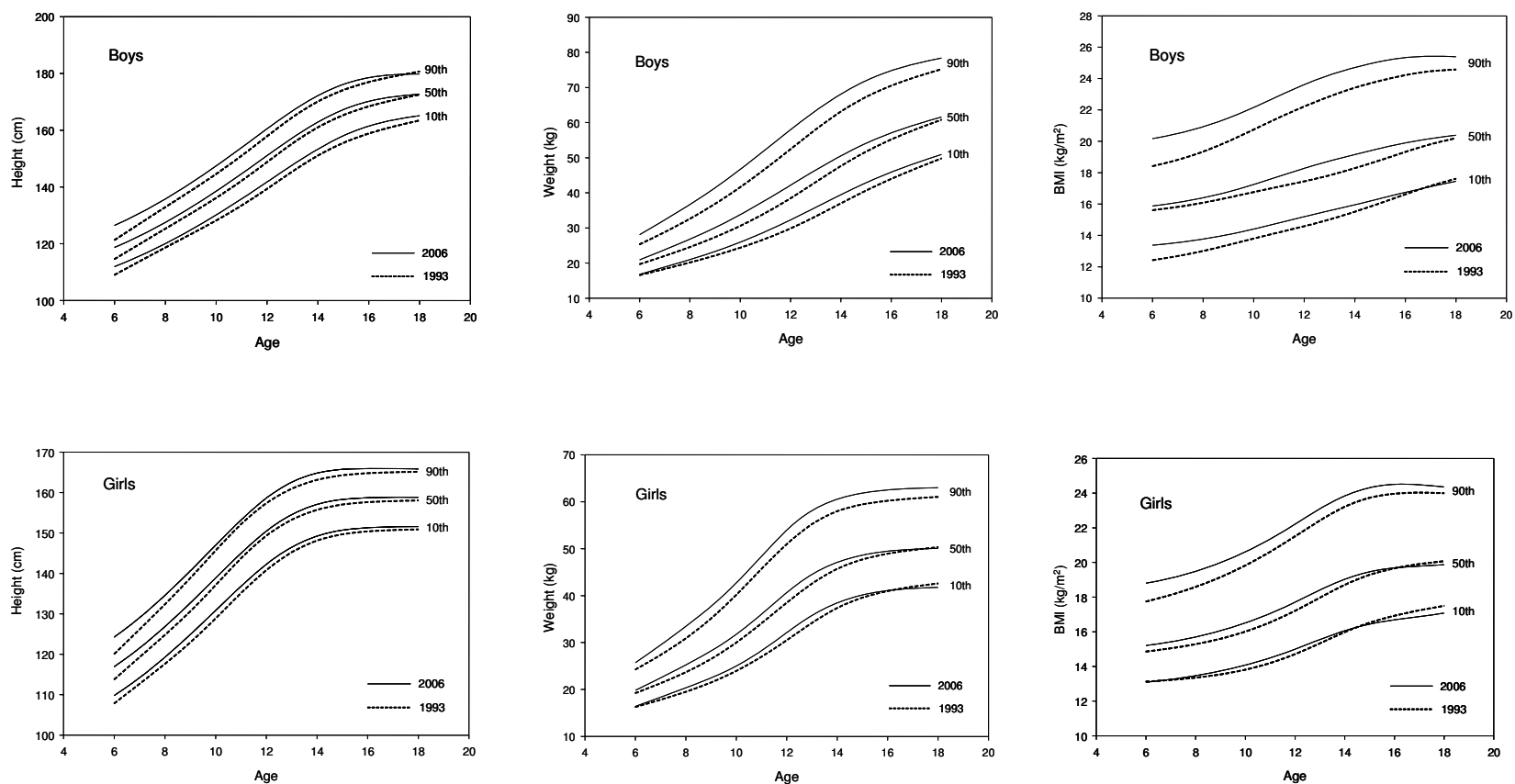

Figure I

Comparison of height $(\mathrm{cm})$, body weight $(\mathrm{kg})$ and body mass index (BMI, $\left.\mathrm{kg} / \mathrm{m}^{2}\right)$ for Hong Kong Chinese children and adolescents aged 6 to 18 y between 1993 and 2005/6.
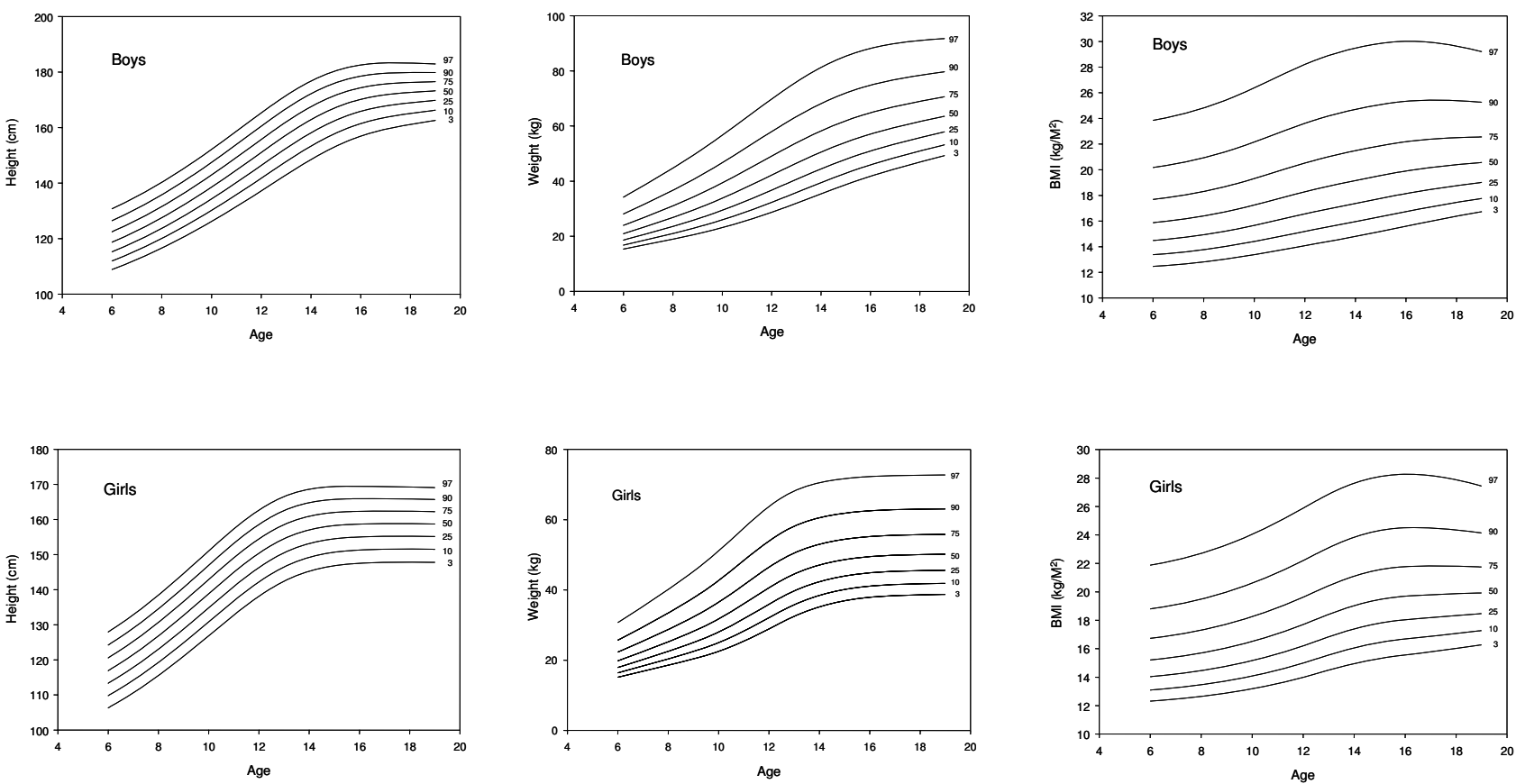

Figure 2

Percentile curves of height $(\mathrm{cm})$, body weight $(\mathrm{kg})$ and body mass index $\left(\mathrm{BMI}, \mathrm{kg} / \mathrm{m}^{2}\right)$ for Hong Kong Chinese children and adolescents aged 6 to 18 y for $2005 / 6$. 
Height increase $(\mathrm{cm} / \mathrm{yr})$ by age \& gender from 1963-1993(d1) \& 1993-2005/6(d2)

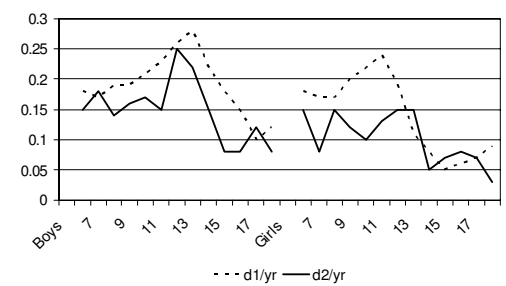

Height increase $(\mathrm{cm})$ by age \& gender from 1963-1993(d1) \& 1993-2005/6(d2)

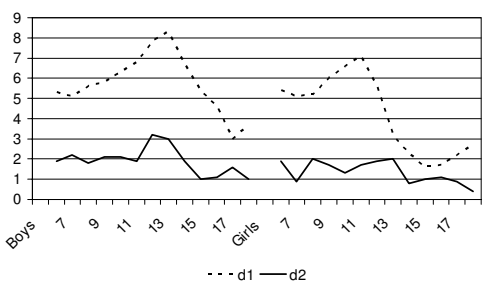

Weight increase $(\mathrm{kg} / \mathrm{yr})$ by age \& gender from 1963-1993(d1) \& 1993-2005/6(d2)

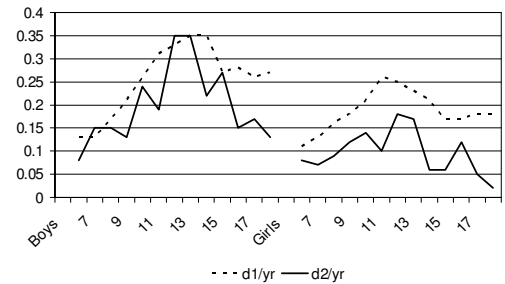

Weight increase $(\mathrm{kg})$ by age \& gender from 1963-1993(d1) \& 1993-2005/6(d2)

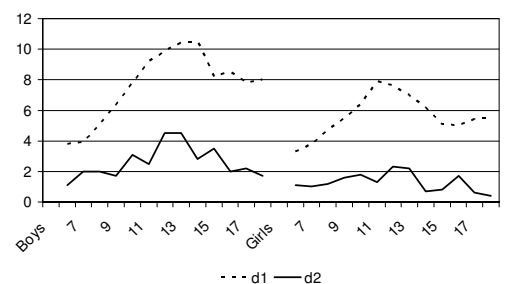

BMI increase per yr by age \& gender from 1963-1993(d1) \& 1993-2005/6(d2)

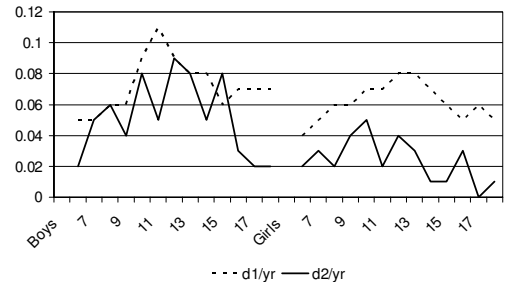

$\mathrm{BM}$ increase by age \& gender from 1963-1993(d1) \& 1993-2005/6(d2)

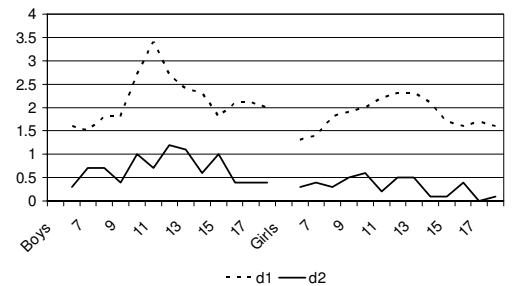

Figure 3

Total and annual difference of mean between 1963 and I 993 (d I) and between I993 and $2005 / 6$ (d2) by gender for height $(\mathrm{cm})$, body weight $(\mathrm{kg})$ and body mass index $\left(\mathrm{BMI}, \mathrm{kg} / \mathrm{m}^{2}\right)$ for Hong Kong Chinese children and adolescents aged 6 to $18 \mathrm{y}$.

evolving progress of the obesity epidemic, and that this particular cohort of children may continue to grow taller and become heavier than current children in the older adolescent age group. Longitudinal surveys or repeated cross-sectional surveys with puberty assessment could help to clarify this further.

WHO has recommended that Ministries of Health, national paediatric associations and other policy makers need to decide whether or not to officially adopt the WHO CGS http://www.who.int/childgrowth. Our study did not include the pre-school age group but we will still need to consider for the 5 to 19 y age group whether Hong Kong should continues to use our current 1993 growth reference charts, whether we should update these charts with our 2005/ 6 data given the secular trends noted or whether we should adopt the new WHO 5 to 19 y charts. More detailed comparisons and discussions with the various stakeholders will be required to make this decision. Meanwhile, our data provides policy-makers with further hard evidence to emphasise the urgency of the problem of increasing obesity. Although the economic implications of the obesity epidemic are still to be fully quantified [22], it is likely that investment in prevention strategies targeting different societal levels now may prevent not only future avoidable death and disability, but will also be cost effective in the longer term.

\section{Conclusion}

Going forward, further studies and regular surveillance of the growth of Hong Kong children are required, both to understand how the obesity epidemic will continue to unfold, as well as to assess the impact of interventions instituted.

\section{Abbreviations}

BMI: Body mass index; IOTF: International Obesity Task Force; MCHC: Maternal and Child Health Centres; SHS: Student Health Service; WHO: World Health Organization.

\section{Competing interests}

The authors declare that they have no competing interests.

\section{Authors' contributions}

HKS coordinated the study, assisted in the supervision of data collection, and took active part in the statistical work. EASN, RYTS and AML prepared the proposal and supervised the study. EMCW and JTFL provided advice in data analysis. GSS, KHM, YW and TFF made substantial contributions to the conception of the study and revising the manuscript. All authors read and approved the final manuscript. 


\section{Acknowledgements}

We thank the school principals, teachers, parents and students that participated in the study. Sophie Leung and Albert Cheung kindly provided advice and information related to the 1993 study. This research project received financial support from Departmental funds and the Hong Kong Paediatric Society

\section{References}

I. World Health Organization: Preventing and managing the global epidemic. Report of a WHO consultation on obesity Geneva: World Health Organization (WHO/NUT/NCD/98.I); 1998.

2. Lobstein T, Baur L, Uauy R, IASO International Obesity Task Force: Obesity in children and young people: a crisis in public health. Obes Rev 2004, 5 Suppl I:4-104.

3. Wang $Y$, Lobstein T: Worldwide trends in childhood obesity. Int J Pediatr Obes 2006, I: I I-25.

4. Wang Y, Mi J, Shan XY, Wang QJ, Ge KY: Is China facing an obesity epidemic and the consequences? The trends in obesity and chronic disease in China. Int J Obesity 2007, 3 I: I77-188.

5. Chang KSF, Lee MMC, Low WD: Standards of the height and weight of Southern Chinese Children. Far East Med J 1965, I:I01-109.

6. Leung SS, Lau JT, Tse LY, Oppenheimer SJ: Weight-for-age and weight-for-height references for Hong Kong children from birth to 18 years. J Paediatr Child Health 1996, 32:103-109.

7. Leung SS, Lau JT, Xu YY, Tse LY, Huen KF, Wong GW, Law WY, Yeung VT, Yeung WK, et al:: Secular changes in standing height, sitting height and sexual maturation of Chinese-the Hong Kong Growth Study, 1993. Ann Hum Biol 1996, 23:297-306.

8. Leung SS, Cole TJ, Tse LY, Lau JT: Body mass index reference curves for Chinese children. Ann Hum Biol 1998, 25:169-174.

9. Cole TJ, Bellizzi MC, Flegal KM, Dietz WH: Establishing a standard definition for child overweight and obesity worldwide: international survey. BMJ 2000, 320:1240-1243.

10. Healy HJ: Statistics of Growth Standards. In Human Growth. A comprehensive treatise: methodology, ecological, genetic and nutritional effects on growth 2nd edition. Edited by: Falkner F, Tanner JM. New York: Plenum Press; 1986:47-58.

II. Sallis JF, Strikmiller PK, Harsha DW, Feldman HA, Ehlinger S, Stone EJ, Williston J, Woods S: Validation of interviewer- and selfadministered physical activity checklists for fifth grade students. Med Sci Sport Exer 1996, 28:840-85I.

12. Cole TJ, Green PJ: Smoothing reference centile curves: the LMS method and penalized likelihood. Stat Med 1992, I I:1305-1319.

13. Chang KSF: Growth of Hong Kong Children. In PhD Thesis Hong Kong University; 1964.

14. Ji CY, Working Group on Obesity in China: Report on childhood obesity in China (I)-body mass index reference for screening overweight and obesity in Chinese school-age children. Biomed Environ Sci 2005, I 8:390-400.

15. de Onis M, de Onis M, Onyango AW, Borghi E, Garza C, Yang H, WHO Multicentre Growth Reference Study Group: Comparison of the World Health Organization (WHO) Child Growth Standards and the National Center for Health Statistics/ WHO international growth reference: implications for child health programmes. Public Health Nutr 2006, 9:942-947.

16. de Onis M, Onyango AW, Borghi E, Siyam A, Nishida C, Siekmann J: Development of a WHO growth reference for school-aged children and adolescents. B World Health Organ 2007, 85:660-667.

17. Wang Y, Moreno LA, Caballero B, Cole TJ: Limitations of the current world health organization growth references for children and adolescents. Food Nutr Bull 2006, 27:SI75-SI88.

18. Flegal KM, Tabak CJ, Ogden CL: Overweight in children: definitions and interpretation. Health Educ Res 2006, 2 I:755-760.

19. WHO EC: Appropriate body-mass index for Asian populations and its implications for policy and intervention strategies. Lancet 2004, 363:157-163.

20. Wang Y: Epidemiology of childhood obesity-methodological aspects and guidelines: what is new? Int J Obes Relat Metab Disord 2004, 28(Suppl 3):S2 I-S28.
21. Wang Y: Is obesity associated with early sexual maturation? A comparison of the association in American boys versus girls. Pediatr 2002, I I 0(5):903-I0.

22. McCormick B, Stone I: Economic costs of obesity and the case for government intervention. Obes Rev 2007, 8:161-164.

\section{Pre-publication history}

The pre-publication history for this paper can be accessed here:

\section{http://www.biomedcentral.com/1471-2458/8/320/pre} pub
Publish with Bio Med Central and every scientist can read your work free of charge

"BioMed Central will be the most significant development for disseminating the results of biomedical research in our lifetime. "

Sir Paul Nurse, Cancer Research UK

Your research papers will be:

- available free of charge to the entire biomedical community

- peer reviewed and published immediately upon acceptance

- cited in PubMed and archived on PubMed Central

- yours - you keep the copyright

Submit your manuscript here:

http://www.biomedcentral.com/info/publishing_adv.asp
BioMedcentral 